\title{
Early clinical experience with the new Amplatzer Ductal Occluder II for closure of the persistent arterial duct
}

\author{
M P B Goonetilleke ${ }^{1}$, U A Jayarathna ${ }^{2}$, H A M Inthisar ${ }^{2}$, N D Vithanage ${ }^{2}$, D R Palangasinghe ${ }^{2}$, \\ P S Hettiarachchi ${ }^{2}$, P M W Madanayake ${ }^{2}$
}

Sri Lanka Journal of Child Health, 2014; 43(4): 201-204

\begin{abstract}
Objective: To describe early single-centre clinical experience with the Amplatzer Ductal Occluder II (ADO II).

Method: Children with a haemodynamically significant patent ductus arteriosus (PDA) who underwent percutaneous trans-pulmonary closure with Amplatzer Ductal Occluder II (ADO2) were included. Data was collected from computer based patient records.
\end{abstract}

Results: Trans-pulmonary PDA closures using ADO 2 were undertaken in 32 children (22 females) with a mean age of 1year 9 months (range 5 months to 10 years) and a mean weight of $8.2 \mathrm{~kg}$ (range $4.2-25 \mathrm{~kg}$ ). Complete occlusion was noted pre-discharge in $31(97 \%)$ patients. One $(3 \%)$ had residual shunting after deployment followed by embolization to the left pulmonary artery on the third day of the procedure. One (3\%) had mild flow acceleration in the left pulmonary artery and another $(3 \%)$ had mild aortic flow obstruction following the procedure. At 7 and 30 days, echocardiography confirmed complete ductal occlusion without need for further intervention in all $31(97 \%)$ successful cases.

Conclusion: ADO II is highly effective in rapid occlusion of morphologically varied small to moderate-sized PDAs.

(Key words: Ductal occluder; patent ductus arteriosus; trans-pulmonary; residual shunting)

\section{Introduction}

The reported incidence of patent ductus arteriosus (PDA) in infants ranges from 0.138 to 0.8 per 1000 live births ${ }^{1,2}$.Transcatheter PDA closure has gained acceptance over surgery because of its cosmetic

${ }^{1}$ Consultant Paediatric Cardiologist, ${ }^{2}$ Medical Officer, Paediatric Cardiology Unit, Teaching Hospital Karapitiya
(Received on 16 February 2014: Accepted after revision on 14 March 2014)

benefits, shorter hospital stay and absence of pain associated with a thoracotomy. Since the initial description by Portsmann et al of nonsurgical closure of PDA the percutaneous approach has become standard clinical practice ${ }^{1}$. Coils and devices have broadened the range of patients and anatomies treatable with percutaneous techniques ${ }^{3-}$ ${ }^{6}$. The ADO2 device provides a solution for the closure of small to moderate-sized PDAs. The $\mathrm{ADO} 2$ device is a modification of the ADO1 device as produced by AGA Medical Corporation. It is one of the range of vascular occlusion devices based on nitinol wire meshes shaped in sequential lobes. $\mathrm{ADO} 2$ is characterized by two low-profile retention discs for placement in the aorta and pulmonary artery (PA). Connecting waist of variable diameter and length for positioning within the PDA itself is attached to the retaining discs by two articulations. This allows the positioned, relatively soft device to adapt to the patient's anatomy rather than distorting the anatomy to its shape.

\section{Objective}

To describe the early single-centre clinical experience with the Amplatzer Ductal Occluder II (ADO II)

\section{Method}

Children presenting with a haemodynamically significant PDA to Teaching Hospital (TH) Karapitiya, Galle, Sri Lanka, who underwent percutaneous closure with the ADO2 were included in this study. In instances where the PDA was larger than $5.5 \mathrm{~mm}$ in diameter, use of the device was not considered. Patients with additional cardiac anomalies requiring surgical correction were referred for surgery as were patients $<3 \mathrm{~kg}$ in weight. Data collected from computer based patient records included demographic, clinical, and echocardiographic parameters.

The trans-pulmonary technique for device deployment was adopted. Initially an aortogram 
was performed using a pigtail catheter. The sizing of the device is based upon the waist diameter and length measured by angiography. The duct is crossed from the PA and the aortic retainer is then exposed in the main aorta and the delivery system withdrawn to allow for the waist to be deployed in the duct itself. The pulmonary retainer is then exposed against the pulmonary arterial wall. Device positioning was confirmed by aortography using a NIH catheter positioned in the aorta. All patients were treated with pre-procedural intravenous cefuroxime $(30 \mathrm{mg} / \mathrm{kg}$ ) with additional three doses post-procedurally. Intravenous heparin $(50 \mathrm{U} / \mathrm{kg}$ ) was administered at the commencement of each procedure. All patients underwent echocardiography on the next day, after 7 days and at 30 day follow-up visits.

\section{Results}

The age groups are shown in Table 1.

Table 1

Age Groups

\begin{tabular}{|c|c|}
\hline Age group & No. of patients \\
\hline$\leq 1$ year & 15 \\
\hline 1-2 years & 09 \\
\hline 2-5 years & 07 \\
\hline 5-10 years & 01 \\
\hline
\end{tabular}

Of the 32 patients, 10 were male and 22 were female. Ten patients had weights from $3.1-6 \mathrm{~kg}, 16$ had weights from $6.1-10 \mathrm{~kg}, 5$ had weights from $10.1-15 \mathrm{~kg}$ and one had a weight over $15 \mathrm{~kg}$. Angiographic measurement of the PDA size is shown in Table 2.

Table 2

Angiographic measurement of the $\mathrm{PDA}$ size

\begin{tabular}{|c|c|}
\hline PDA size (mm) & No. of patients \\
\hline $1-2$ & 11 \\
\hline $2.1-3$ & 10 \\
\hline $3.1-4$ & 07 \\
\hline $4.1-5$ & 03 \\
\hline$>5.1$ & 01 \\
\hline
\end{tabular}

The PDA device size is shown in Table 3.

Table 3

$P D A$ device size

\begin{tabular}{|c|c|}
\hline Device size & No. of patients \\
\hline $6 \times 6$ & 10 \\
\hline $6 \times 5$ & 01 \\
\hline $6 \times 4$ & 04 \\
\hline $5 \times 6$ & 05 \\
\hline $5 \times 4$ & 03 \\
\hline $4 X 6$ & 02 \\
\hline $4 X 4$ & 04 \\
\hline $3 \times 6$ & 03 \\
\hline
\end{tabular}

From May 2012 until January 2014 transvenous PDA closures using ADO2 were undertaken in 32 children (22 females and 10 males). $6 \mathrm{~mm} \times 6 \mathrm{~cm}$ ADO2 was the commonly used device in our series. Mean age was 1 year 9 months (range 5 months to 10 years) with a mean weight of $8.2 \mathrm{~kg}$ (range $4.2-25 \mathrm{~kg}$ ). The mean ductal diameter was $2.8 \mathrm{~mm}$ (range $1.2-5.1 \mathrm{~mm}$ ). ADO II was released in all 32 children. One (3\%) patient had residual shunting after deployment of ADO II followed by embolization to the left PA on the third day of the procedure. This child underwent surgical closure of the PDA after the surgical removal of the embolized device. Complete occlusion was noted pre-discharge in the remaining 31 (97\%) children. One of these 31 children had mild flow acceleration in the left pulmonary artery (LPA) and another had mild aortic flow obstruction following the procedure. These 2 children are doing quite well at present with good weight gain despite still having mild LPA origin narrowing and mild obstruction to the descending aortic flow due to the presence of the device. These are common complications following PDA device closure and are usually overcome with growth of the pulmonary artery. At 7 and 30 days, echocardiography confirmed complete ductal occlusion without need for further intervention in all 31(97\%) successful cases.

\section{Discussion}

Transcatheter closure procedures have been performed with high success rates both in children and adults ${ }^{3-17}$. Due to advances in diagnostic and therapeutic modalities diagnosis and treatment of PDA can be accomplished at a relatively early age e- $^{5}$ ${ }^{7}$. Thanopoulos et al ${ }^{14}$ reported success rates of $95 \%$ and $98 \%$ soon after and one month after device implantation in patients with a mean age of 3.6 years.

The ADO2 device provides a solution for the closure of small to moderate-sized PDAs in children $^{13,14}$. We have demonstrated that percutaneous treatment with $\mathrm{ADO} 2$ can be realized with lower complication and residual shunt rates. The immediate and short term follow up success rate (complete occlusion) for duct occlusion by ADO2 at 24 hours, 7 days and 1 month was $97 \%$ respectively in our series which compares favourably with data reported using Amplazter ADO2 devices ${ }^{7}$. The multiple layers of nitinol allow for rapid ductal occlusion which reduces residual shunt risks. The ability to position the ADO2 such that each of the retention discs assumes its independent orientation significantly reduces the risk of protrusion, anatomical distortion and displacement which has resulted in a 97\% $(n=31)$ success rate of device deployment in our series 
with only one $(3 \%)$ re-intervention due to device dislodgement which compares favourably with reported data $^{7}$.

The ADO2 device was designed by the manufacturers with the express intention that the retaining discs would be positioned in the aorta and PA. However, in the presence of a large ampulla, the aortic retaining disc will be positioned within the ampulla and not the aorta. This position makes the aortic disc to appear spherical while the pulmonary disc to be flattened giving a disfigured orientation after deployment although this is the accepted configuration in case of a PDA with a large ampulla. When approached transvenously which we practise coupled with the soft and flexible nature of the Amplazter ADO 2 devices, the aortic disc can be well positioned in the ampulla without protruding to the aorta, while still allowing the rest of the device to assume its intended position. This has resulted only $3 \%(n=1)$ of cases with mild obstruction to the aortic flow in our series.

In case of a short duct, the central waist may protrude into the $\mathrm{PA}$, leaving the $\mathrm{PA}$ retaining disc redundant. This occurs even more so if the device is significantly oversized. As such, the shorter device will usually be applicable unless the duct is extremely long. In our experience, this positioning was problematic only in one case (3\%) with 18 $\mathrm{mmHg}$ pressure gradient noted across the left PA origin. Correct and high quality ductal imaging techniques available in our unit allowed us to accurately assess the ductal anatomy and the size which helped us to select the appropriate sized device thus preventing any unwanted pulmonary flow obstructions.

Embolization during release of the device is one of the important complications of the procedure ${ }^{7-9}$. Embolization can occur in systemic and generally in pulmonary artery ${ }^{7-9}$. In a published series of 27 cases, Forsey et al ${ }^{8}$ reported displacement of the device $(n=1)$ and embolization $(n=1)$. They attributed development of these complications to underestimation of ductal diameter secondary to spasm of the ductus arteriosus induced by catheterization. In our study, as a procedural complication only one $(3 \%)$ device embolization to the PA was observed three days after the device deployment. Although the selected size of the device matched with the measurements of the acquired ductal images we assume this to be attributable to underestimation of ductal diameter secondary to spasm of the ductus arteriosus induced by catheterization.
Vascular injury to the femoral artery and the vein at the local access site, haematoma formation and damage to the local soft tissues have been reported in published data $^{5-8}$. In our series all cases had palpable popliteal pulses 6 hours following the procedure and intravenous heparin infusion was not required in any child. Infection of the local vascular access site was not reported and vascular surgical intervention was not needed in our series. Although this is mainly attributable to the operator experience the ADO2 design and flexibility has also allowed delivery with 4 or $5 \mathrm{~F}$ delivery catheters with minimal local tissue and vascular injury as compared to ADO 1 which needs a minimum of $6 \mathrm{~F}$ delivery system to deliver the smallest available device.

\section{Conclusions and recommendations}

- $\quad$ ADO II is highly effective at providing rapid occlusion of morphologically varied small to moderate-sized PDAs.

- Occluder design allows delivery with 4 or $5 \mathrm{~F}$ delivery catheters with minimal local tissue and vascular injury.

- Stable occluder position is dependent on accurate device sizing, correct positioning of both aortic and pulmonary discs, good quality imaging to visualize device configuration and operator experience.

- Flexibility of the articulations allows this device to simplify the treatment in a range of patients and specific ductal anatomies that are more challenging.

- A larger range of sizes and configurations of this occluder may be required to successfully occlude all ductal sizes and morphologies.

\section{References}

1. Fyler DC, Buckley LP, Hellenbrand WE, et al. Report of the New England Regional Infant Cardiac Program. Pediatrics 1980; 65(Suppl):398.

2. Botto LD, Correa A, Erickson JD. Racial and temporal variation in the prevalence of heart defects. Pediatrics 2001; 107(3): 1 . http://dx.doi.org/10.1542/peds.107.3.e32

3. Cambier PA, Kirby WC, Wortham DC. Moore JW. Percutaneous closure of the small (less than $2.5 \mathrm{~mm}$ ) patent ductus arteriosus using coil embolization. American Journal of Cardiology 1992:69:815-6. http://dx.doi.org/10.1016/00029149(92)90514$\underline{\mathrm{Y}}$ 
4. Rosenthal E, Qureshi SA, Reidy J, et al. Evolving use of embolisation coils for occlusion of the arterial duct. Heart 1996:76:525-30.

http://dx.doi.org/10.1136/hrt.76.6.525

5. Pass RH, Hijazi Z, Hsu DT, et al. Multicenter USA Amplatzer patent ductus arteriosus occlusion device trial: Initial and one-year results. Journal of the American College of Cardiology 2004:44:513-9.

http://dx.doi.org/10.1016/j.jacc.2004.03.074

6. Gudausky TM, Hirsch R, Khoury PR, Beekman RH. Comparison of two transcatheter device strategies for occlusion of the patent ductus arteriosus. Catheterization and Cardiovascular Interventions 2008; 72:675-80.

http://dx.doi.org/10.1002/ccd.21669

7. Forsey J, Kenny D, Morgan G, Hayes A, Turner M, Tometzki A, et al. Early clinical experience with the new Amplatzer Ductal Occluder II for closure of the persistent arterial duct. Catheterization and Cardiovascular Interventions 2009;74:615-23. http://dx.doi.org/10.1002/ccd.22055

8. Bilkis AA, Alwi M, Hasri S, Haifa AL, Geetha K, Rehman MA, et al. The Amplatzer duct occluder: experience in 209 patients. Journal of the American College of Cardiology 2001; 37:258-61.

http://dx.doi.org/10.1016/S07351097(00)0109 $\underline{4-9}$

9. Santoro G, Gaio G, Carrozza M, Palladino MT, Russo MG, Calabrò R. Large patent ductus arteriosus closure with multiple controlled-release coils. International Journal of Cardiology 2007;116:425-6.

http://dx.doi.org/10.1016/j.ijcard.2006.03.079

10. Spies C, Ujivari F, Schräder R. Transcatheter closure of a $22 \mathrm{~mm}$ patent ductus arteriosus with an Amplatzer atrial septal occluder. Catheterization and Cardiovascular Interventions 2005; 64:352-5. http://dx.doi.org/10.1002/ccd.20283
11. Prada F, Mortera C, Bartrons J, Rissech M, Jiménez L, Carretero J, et al. Percutaneous treatment of atrial septal defects, muscular ventricular septal defects and patent ductus arteriosus in infants under one year of age. Rev Esp Cardiol 2009; 62:1050-4. http://dx.doi.org/10.1016/S03008932(09)7210 $\underline{4-9}$

12. Park YA, Kim NK, Park SJ, Yun BS, Choi JY, Sul JH. Clinical outcome of transcatheter closure of patent ductus arteriosus in small children weighing $10 \mathrm{~kg}$ or less. Korean Journal of Pediatrics 2010;53:1012-7. http://dx.doi.org/10.3345/kjp.2010.53.12.1012

13. Baspinar O, Irdem A, Sivasli E, Sahin DA, Kilinc M. Comparison of the efficacy of different-sized Amplatzer duct occluders (I, II, and II AS) in children weighing less than 10 kg. Pediatric Cardiology 2013;34:88-94. http://dx.doi.org/10.1007/s00246-012-0393-6

14. Thanopoulos BV, Eleftherakis N, Tzannos K, Stefanadis C, Giannopoulos A. Further experience with catheter closure of patent ductus arteriosus using the new Amplatzer duct occluder in children. American Journal of Cardiology 2010;105:1005-9.

http://dx.doi.org/10.1016/j.amjcard.2009.11.03 $\underline{0}$

15. Porstmann W, Wierny L, Warnke H. Closure of persistent ductus arteriosus without thoracotomy. Ger Med Mon 1967;12:259-61.

16. Jacob JLB, Braile DM. Current treatment of the persistent arterial duct. Rev Bras Cir Cardiovasc 2003;18:350-8. http://dx.doi.org/10.1590/S0102763820030004 $\underline{00009}$

17. Pass RH, Hijazi Z, Hsu DT, Lewis V, Hellenbrand WE. Multicenter USA Amplatzer patent ductus arteriosus occlusion device trial: initial and one-year results. Journal of the American College of Cardiology 2004; 44:5139. http://dx.doi.org/10.1016/j.jacc.2004.03.074 